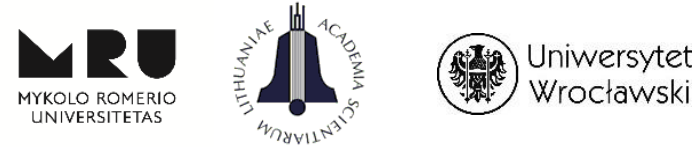

\title{
SIMPLIFICATION OF THE RURAL DEVELOPMENT PROGRAMME: EFFECTIVENESS OF THE MANAGEMENT DECISION IN THE FIELD OF COMMON AGRICULTURAL POLICY
}

\author{
Svilen KOLEV \\ University of National and World Economy (UNWE), Sofia, Bulgaria \\ E-mail: svilenkolev@abv.bg \\ Roumiana ATANASSOVA \\ New Bulgarian University, Sofia, Bulgaria \\ E-mail: rumiatanassova@yahoo.com
}

doi:10.13165/IE-14-8-2-06

\begin{abstract}
: the present report is intended to analyse and propose methods for the improvement of the process of management decision-making in the field of agriculture in Bulgaria. It will increase the effectiveness and speed up simplification on the basis of analysis of existing gaps and opportunities in the management of funding available under the Rural Development Programme (RDP).It will also significantly reduce bureaucracy. It is important to note that avoiding frequent changes of rules for the implementation of the RDP is an essential condition for smooth operation of the programme.

Impact Assessment is used at the EU level, and it is well known as an assessment tool of the potential economic, social and environmental consequences. This assessment tool was used before new initiatives of the European Commission were proposed, however rarely implemented at Member States level.

The goal of the article is to justify the analyses need of the effects for the RDP measures implementation, using the Balanced Scorecard, Enterprise Resource Planning (ERP) and Customer Relationship Management (CRM). It would allow simplification of the procedures and will increase the effectiveness of the RDP funding.
\end{abstract}


The simplification and the analyse of the effects of the RDP measures funding are a new element of analysis. This analysis has to include the impact, as well as the costs for and benefits of the implementation of each measure.

Economic effectiveness and simplification in the implementation of the different measures of the program are considered. The aim is to achieve optimal management solutions that will generate higher added value.

JEL classification: Q10, Q14, Q18.

Keywords: Simplification, Effectiveness, Rural Development Programme, Decisionmaking process, Balanced Score, Impact Assessment, Enterprise Resource Planning (ERP), Customer Relationship Management (CRM), Common Agricultural Policy

\section{Introduction}

Agricultural Policy is one of the highly regulated on the one hand from the European Union (EU) and on the other hand from the Member States (MS). The management policy for the decision-making process needs improvement and simplification at the Member State level.

For these reasons mix of evaluating and implementing tools are necessary, such as the Impact Assessment, Ex-ante Report, Effects of the implementation of the RDP measures, the Balanced Scorecard, Customer Relationship Management and Enterprise Resource Planning. Theses tools could increase the effectiveness of the implementation of the policy.

The Rural Development Program is part of the Common Agricultural Policy (CAP) of the European Union. Implementation in each Member State is based on the Partnership Agreement (PA). Through this Partnership Agreement, the investments of all funds of the Common Strategic Framework (CSF) are directed to the respective EU Member State.

The synchronized with the Partnership Agreement, Rural Development Program is a powerful tool for implementation of effective or ineffective investments in the rural areas. The Ministry of Agriculture designs the program, but implementation is carried out by respective Agency. The management style of the Implementing Agency determines if the qualitative and the quantitative targets foreseen in the Rural Development Program will be met.

The purpose of this publication is to analyze the process of decision making in Bulgaria regarding the Rural Development Program by the state administration. The report sets out possible options for improving the effectiveness of the decision-making process and contribute to simplification. The approach is based on analysis of the impact of the measures of the Rural Development Program in terms of their effectiveness and value added at the level of Implementing Agency.

It is also necessary to change the logical model. One of the first steps that should be taken is to decentralize the administration of certain measures. The second step is 
simplification by means of creating a "one stop shop" for submission and verification of information.

Namely, the upfront costs of the consultants can be paid directly by the Implementing Agencies. It will ensure that they will receive funds only after completion of tasks. It is possible to pay subsidies for the equipment directly to the company referred to in the project.

Another way of simplification is creating E-portal. It is necessary to have online applications to allow candidates to enter data through the Internet.

Investment potential has to be studies before proceeding with each application. In other words, each project must undergo a check for financial viability prior application.

Transfer options between pillars for financing RDP could be used. Such versatility between Pillar I of the CAP (European Agricultural Fund for Guarantee Fund) and Pillar II of the CAP (European Agricultural Fund for Rural Development) could provide funding for RDP.

Management decision could be improved within the Implementing Agency through Robert Kaplan and David Norton Balanced Scorecard Performance method. The introduction of these methods will optimize the use of resources foreseen under the Rural Development Program.

\section{Analysis of the environment and instruments for management of the Rural Development Program as part of the Common Agricultural Policy}

\subsection{Common Agricultural Policy basic aspects}

EU has three broad intervention areas (direct payments, rural development and market measures).

Pillar I of Common Agricultural Policy (CAP), directs payments - the schemes be compulsory and voluntary, funded by the European Agricultural Guarantee Fund (EAGF).

"Pillar I includes instruments related to the functioning of agricultural markets and the food supply chain (Council Regulation (EC) No 1234/2007) and to direct payments (Council Regulation (EC) No 73/2009) conditional upon statutory management Pillar I measures are mandatory for Member States and, with very few exceptions, there is no co-financing. It ensures the application of a common policy within the Single Market, monitored by an integrated administration and control system (IACS)."1

Mandatory schemes in all Member States (MS) are the basic payment scheme, environmental payments, and payments for young farmers.

\footnotetext{
${ }^{1}$ Commission Staff Working Paper (2011) Impact Assessment, Common Agricultural Policy Towards 2020, SEC(2011) 1153 final/2, page 13, 14
} 
Voluntary schemes (optional for MS) are coupled aid, assistance in areas with natural constraints redistributive payments, multi-direct payments. It is a system of support schemes with different requirements for each scheme. The funding provided for a reduction in payments of $5 \%$ for payments above $€ 150,000$. For young farmers provided $25 \%$ increase in payments for a maximum of five years for areas up to 100 hectares. For small farms, it provides a lump sum determined by MS between 500 to $€ 1250$.

The direct payments by 2016 are so-called complementary national direct payments (or "top-ups"). It is in addition to the European system of basic payments. The maximum amount of Bulgarian national payments for 2014 is $€ 150,186,000$. For 2015 it is $€$ $71,024,000$. The maximum amount in 2014 of national payments for cotton in Bulgaria should not exceed - $€ 556,523$ and for 2015 - 295,687€.

Pillar I of the Common Agricultural Policy concerning market support provides the abolition of the sugar quota, the abolition of the planting of vines and dropping of the aid for skimmed milk powder, silkworms and sorghum. Increase of intervention for beef is foreseen until $85 \%$ of the reference price is applied, introduction flexible crisis management reserves, elimination of milk quotas, removal of private scheme for the storage of butter, creation of marketing term to compensate for market failures is applied. The European Commission (EC) allows the introduction of measures by Member States to prevent crisis situations such as price fluctuations, natural disasters, and climate changes impacts.

Risk management such as harvest and animals insurance is introduces (financial contributions to insurance contracts covering losses of agricultural producers (AP) and participation in mutual funds - a scheme accredited by member state allowing participating agricultural producers to receive compensation during crisis). The emphasis is on tools for stabilizing the income of agricultural producers.

Pillar II of the Common Agricultural Policy - European Agricultural Fund for Rural Development (EAFRD).

"Pillar II - Rural Development Policy (Council Regulation (EC) No 1698/2005) includes measures that aim at improving the competitiveness of the agriculture sector, delivering specific environmental public goods and promoting the diversification of economic activity and quality of life in rural areas. These measures are largely voluntary, contractual, co-financed and delivered within a strategic framework that links policy action to European, national, regional and local needs." 2

Priorities for 2014-2020 rural development at the EU level include fostering knowledge and innovation transfer in agriculture, forestry and rural areas. The aim is an enhancement of the farms viability and competitiveness of all types of agriculture in the regions, promotion of innovative technologies in agriculture and sustainable management of forestry.

\footnotetext{
${ }^{2}$ Commission Staff Working Paper (2011) Impact Assessment, Common Agricultural Policy Towards 2020, SEC(2011) 1153 final/2, page 14
} 
Promotion of good food chain organization is foreseen including agriculture products processing and marketing, animal welfare and risk (hazard) management in agriculture, as well as restoring, preserving and enhancing the ecosystems related to the agriculture and forestry. The Program promotes the resource effectiveness and supports the shift towards a low-carbon economy and climate-resilient economy in the agriculture, forestry and food industry with $30 \%$ of the funds.

Measures within the Common Agricultural Policy for rural development have been developed. It is recommended to implement 17 measures + Leader approach, including strengthening cooperation, including pilot projects, shorten the supply chains, promoting local action groups, new tools for risk management, investments in physical assets for young farmers, collective investments, irrigation, development of small farms and enterprises, producer groups or clusters, organic farming, sharing knowledge - information and counseling schemes for quality of products - advertising campaigns and forest areas development.

The framework of the implementation of the Rural Development Program 2014-2020 provides that each Member State have to determine milestones until 2018 for each priority of the Rural Development Program and set up indicators of achievement. If these are not achieved the foreseen performance reserve of $6 \%$ of the budget of each of the structural and investment funds for each Member State concerned will be relocated. The performance review will be made in 2019. The resources will be relocated to priorities achieved targets. This scheme will be implemented after respective Member State proposal. In case of failing to achieve the goals, suspension of payments is possible or financial corrections could be applied.

The funding under Pillar I (European Agricultural Guarantee Fund) is up to $100 \%$, except for the market measures. Funding under Pillar II (European Agricultural Fund For Rural Development ) will range from $53 \%$ to $95 \%$. For measures funded via transfer from Pillar I it is provided that funding will be $100 \%$. $25 \%$ of the resources could be transferred from Pillar I and Pillar II. From Pillar II to Pillar I the transfer is limited to 10\%. At least $30 \%$ of the funding under the Rural Development Program should be spent on measures that have a positive impact on the environment and climate change. At least $5 \%$ of the funding under the Rural Development Program should be spent on Leader approach.

\subsection{Effectiveness - Combination of evaluating and implementing tools to increase} the effectiveness include Impact assessment, Ex-ante report, effects of the implementation of the RDP measures, the Balanced Scorecard, CRM and ERP.

The implementation of agricultural policy at the Member State level is mainly through the Rural Development Programme.

At Impact Assessment is used at the EU level as an evaluation tool of the potential economic, social and environmental consequences. New initiatives are evaluated before the European Commission proposal. 
At the Member State level ex-ante report is required, and Impact Assessment of the Rural Development Program is rarely performed.

The goal of the paper is to underlie that the analyse of effects of the implementation of the RDP measures, the Balanced Scorecard and Enterprise Resource Planning could improve decision-making.

Effects of the implementation of the RDP measures is a new element of analyses. This analysis have to include analysis of the impact as well as of the costs and benefits of the implementation of each measure.

What would the analyse of the effect of each measure implementation include? This is a detailed and systematic assessment of the potential impacts of each measure, in order to be evaluated if it is likely to achieve the desired objectives and impact. The need of analysis of effect of each Rural Development Program measures stems from the fact that the implementation of the measures often have multiple effects and it is difficult to predict the results without detailed study of positive and negative effects in order to determine the value added.

The economic approaches towards the implemention also highlight the risk that administrative costs may outweigh the benefits. From this perspective the main purpose of the analysis is that the implementation of each measure will contribute to the improvement of the welfare - i.e. the benefits will outweigh the costs. The analysis of each Rural Development Program measures impact can be applied in comparative context with different means for achievement of the objective pursued by analyzing and comparing the results.

\subsection{Decision making process in the agriculture sector in Bulgaria. Existing gaps and opportunities in the use of funding available under the Rural Development Programme.}

The decision making process and management style of the Rural Development Programme implementation are generally political. Political decisions determine the guidelines for development and the methods of implementation of agreed policies. The Economic viability of investments is not analysed during the implementation of the programme measures. This leads to a mismatch between the objectives set at national level, due to the relatively short planning period applied. The main objective is to report on the level of funds spend, not taking into account the long-term positive perspective for the economy and population. This approach is lacking flexibility in Rural Development Program management. Complex management procedures are used that do not give a clear picture of the state of the organization. Generally, mainly financial parameters in terms of funds spend are observed, not the overall situation for the effects of implementation. To a large extent, the financial and accounting information available does not give a clear picture of the effects of the measures implemented.

Concerning the information systems, a data base for Rural Development Program implementation is available. There is a general accounting system. Currently, a 
multifunctional information system as Enterprise Resource Planning (ERP) system is missing. The lack of ERP determines the absence and / or distortion of information in real time that prevents appropriate decisions making the process at management level. Such system is recommended for effective Rural Development Program implementation.

As a matrix for implementing the ERP and CRM model, it is possible to use Robert $\mathrm{S}$. Kaplan and David P. Norton approach described in The Balanced Scorecard: Translating Strategy into Action book.

The balanced scorecard system includes "4 perspective":

- "Financial";

- "Customer";

- "Internal Business Processes";

- "Learning and Growth ".

If necessary, to the main lines other directions can be added depending on the practical need.

In Strategy Maps - Converting Intangible Assets into Tangible Outcomes book Robert S. Kaplan and David P. Norton, point out that the strategy chosen for the application of different perspectives, must be adapted to the mode of implementation and "must be integrated and coordinated in order to lead to value proposition reflecting the strategy of the entire company"3.

The Balanced Scorecard system through Enterprise Resource Planning could be set as a management module for Rural Development Program. It would be applicable to the financial state of the Paying Agency as well as for the guidelines for the implementation of the respective measures of the Rural Development Program.

The relations with beneficiaries (customer) should be set as part of the system. Electronic application, filling in information in the system and checking of measurable indicators as well as feed-back forms for standardized operations as issue of incoming number of the applications, checking of the business plan for financial compliance, implementation and reporting, have to be part of this module. A call center and facilities for processing of complaints could be added to the same module.

The internal business processes would include establishing of different forums for communication and exchange of good practices, processing of tasks, establishing of ad-hock working groups and contact points with external organizations for problem-solving at management level.

As Robert S. Kaplan and David P. Norton mention "The training and development in each organization are founded on three basic sources: Human resources, systems and organizational procedures" 4 . In this context, knowledge development and learning perspective

\footnotetext{
${ }^{3}$ Kaplan, R.S. and Norton D.P (2006). Strategy Maps Converting Intangible Assets into Tangible Outcomes, Page 332 Page.39

${ }^{4}$ Kaplan, R.S. and Norton, D.P (2005). The Balanced Scorecard: Translating Strategy into Action,
} 
for the promotion of the employees is fundamentally important for creating of so called skeleton of the organization. This includes key experts as memory of the organisation. They are to develop knowledge and skills in specific areas. The training and self-education are composite parts of this process. The new knowledge and experience would give the opportunity for of Rural Development Program in maximum flexible and simple form and at the same time would provide for the simplified application of Regulations, procedures and guides for work.

The introduction of these methods would be the basis for improvement of the effectiveness and efficiency of the state administration decision-making processes in the field of rural development policy. This would provide decision makers with data base on which to make informed decisions for implementation of agricultural policy.

Currently the system for implementation of agricultural policies and particularly the Rural Development Program is standardized in all Member States, with centralized control by the European Commission. The aim is to spend the Rural Development Program funds, broken down by measures and axes. During the mid-term evaluation of program implementation, indicators of achievement are measured. As a rule, regardless of the assessments, program alteration is not allowed. In fact, the programs achieve the planned indicators, increasing the capital investments, but do not necessarily contribute to the economic development of the region or country concerned.

It is important to introduce analyse of the effects of the implementation of the Rural Development Program measures on the regional economy. This analysis has to include evaluating of the impact as well as of the costs and benefits of the implementation of each measure.

What does it mean? The implementation of a particular Rural Development Program policy requires resources - for salaries, benefits, training, jobs, software, hardware, and cofinancing from the state. The analyse of the impact have to determine what will be expenses and benefits for the implementation. The principle can be very simple - including the unit for the administrative expenses and the administrative burden for beneficiaries plus Rural Development Program financing compared to financing impact. The analysis will show what is the positive effect of the investment for the community.

If such analyse is in place, measures for which positive effect of investment is low, will be scored at the end of the list for implementation. Measures with high added value will be prioritised for implementation.

The marker for positive measure impact would be 1 invested unit brings minimum 1 unit back. The negative marker will be if 1 unit of investment does not return 1 unit.

\subsection{Simplification}

The optimization of RDP implementation processes leads to simplifying the implementation of the program. It will significantly reduce bureaucracy and hence simplifies the implementation of the CAP. It is important to note that avoiding frequent changes of rules 
for the implementation of the RDP is an essential condition for smooth operation of the programme.

\subsubsection{Change of logic}

Currently, procedures are complicated, and it is intended effect to stress on the weight when implementing the program. It is necessary to change this for the 2014-2020 programming period. Long coordination procedures that are labor intensive, slow and inefficient have to be eliminated. If checklists and instructions are well-developed, check with the Yes / No choice of expert and inspection for the work carried out by subsequent expert is sufficient and respecting the four eyes principle. The signature of Team Leader, Head of Department, Deputy Executive Director and Executive Director have to be dropped off from the procedures.

One of the first steps that should be taken is to decentralize the administration of certain measures. The criteria for this should mainly be a large volume of users for small amounts of subsidy. What is a major problem when considering projects is that the project proposals are submitted in the regional structures throughout the country, and all this documentation goes to one point - the HQ. A so-called effect of the neck of the bottle is present, i.e., there is no possibility to evaluate them in time and the time of their completion is extended for an indefinite period. This result is largely because most of the projects that generate this effect are small projects for a small amount of financing of the total amount for the implementation of the program. Therefore, the main direction for the smooth transition to a decentralized implementation of the RDP is to separate these measures that have many candidates, but for small amounts of assistance. Their administration should be delegated at the regional level. Smooth delegation of functions should make These changes.

Creating a "one stop shop" for submission and verification of information

These are services and information provided, related to state and municipal entities, concerning the implementation of the RDP. A major problem is that candidates receive different information before and during the application process. This is due to the different structures that carry out the same or similar activity, which is duplication, leading to different, mostly confusing information from the various departments and ultimately the function of these services has been distorted. It is, therefore, necessary to have only one point, where everyone will communicate only with experts providing clear information.

This would be the "one stop shop", where all the information necessary would be provided for all lines of funding.

Currently the budget for public and private consultants is provided in the RDP and to some extent thanks to the previous programming period network of consultants under the RDP has already been established, but they are not fully utilized. To a large extent these consultants do not do any work or their workload is not much. It is, therefore, necessary to make publicly available register for evaluating the performance of these consultants and continue only with those who are professional and have errors -free performance (evaluating 
the conformity of the work). Such arrangement would allow candidates to know to whom to turn to and what service will get.

Following this logic of work, some activities for the implementation of the RDP, as reporting on implementation, processing of statistics, ranking and selection of projects, may be delegated to various external organizations.

A small change can be made, namely the upfront costs to be paid directly by the Implementing Agencies to the consultants. It will ensure that they will receive funds only after completion of the job. Also, it is possible to pay subsidies for the equipment directly to the company referred to in the project. In this case transfer of funds from the account of the paying agency to the account of the farmer will be made and then to the account of the trader will be avoided.

Thus, public resources would not be lost. On the other hand, this will allow farmers or food processing companies not to deal with paperwork and expenses that are covered by the program and accordingly they will not be held as responsible for financial discrepancies.

\subsubsection{E-portal}

Preparation and submission of the applications / payment are costly and timeconsuming, in fact, it is an administrative burden for the RDP applicants. The same applies to the state administration.

In parallel with the simplification of the rules of admission, review and implementation of the program, it is necessary to implement the next step, which is related to the so-called e-government. E-government in the case of the RDP would be a unified system for collecting, processing and performance management to authorizing the expenditure as a final product of the work of applicants and the administration. The use of this tool is possible thanks to Internet and the relevant e-services. Another important factor is that the processing of documents and submission is mainly done by consultants who frequently use electronic means of processing and submission of information. Not least the electronic submission will reduce doubts that there is registration of application only within the deadline and subsequent "addition" of the whole project.

Of course, it is necessary to have paper and online applications in place in order to allow candidates without Internet access to proceed with submissions.

The applications could be via the Paying Agency (PA) website. In order to be operational, a database with detailed instructions for each step has to be provided for filling in the information. This portal may have several levels to implement different options according to the progress in the implementation of such systems, as well as the preparedness of the administration and users.

The first stage can be the introduction of filling in the database information about beneficiaries. It will be a passive e-page providing an opportunity for collecting information that is currently filled in by employees of PA. It is one-way communication with users, which allows downloading application forms and documents by users. 
The second stage is two-way interaction with users. It implies the creation of a portal that allows the exchange of information with possibility for completion and submission of information by candidates to the administration and from administration to beneficiaries. This stage is to enable not only filling in and submitting applications, but also monitoring of the status, communication between users and administration, etc. At this stage, it is already electronic processing of files and will save time for both sides.

The last stage is customizable: proactive and automatic control, which is the highest level of computing. This stage involves not only all the previous steps, but it also includes pre-filled with basic information forms. At this stage, it would not be necessary to provide already obtained by the Paying Agency information. The system would monitor and indicate marked deadlines, correct erroneous data and so on.

Achievement of the latter element is the key to accelerating and simplify the application process for the review of projects and reduce costs for administration and users. At the moment, only the first level of e-services is achieved.

In the Paying Agency, except the said electronic portal and Enterprise Resource Planning implementation is possible to combine current system also with the system for managing relationships with users - so called Customer Relationship Management (CRMsystem) - a typical example of such systems are call center service and processing and analysis of views and experiences through social networking for companies, products and services to users of the RDP.

\subsubsection{Financing}

A major problem with application and approval of projects is the lack of pre-funding. In some cases, projects for which it is clear that no pre-funding are selected. This is a risk for losing funds, which can be directed towards projects that have assured pre- financing. This problem can be solved in advance in few steps.

For each application investment capability analyze has to be performed. In other words, each project must undergo a check for financial viability prior application. For example, if applying for a project that is for a maximum threshold for a measure and the candidate is only registered for a month, the probability to get a loan is unlikely. It means that new companies need to have a certain limit of initial funding.

Another option for funding can be applied by means of transfer between pillars. For

measures financed with funds transferred from Pillar I of the CAP (European Agricultural Fund for Guarantee Fund) to Pillar II of the CAP (European Agricultural Fund for Rural Development), 100\% financing is provided. For the programming period, 2014 - 2020, from Pillar I to Pillar II $25 \%$ of the resource may be transferred and these $25 \%$ can be used for prefinancing of the project proposals.

Some of these $25 \%$ transferred funds can be directed if necessary for efficient and flexible security systems (insurance and guarantees for the agricultural sector) in order to 
avoid increasing and more and more frequent crises as well as to preserve the income of the employed in the agricultural sector.

\subsubsection{Regional planning}

The Rural Development Programme support is at a different level for various sectors, without taking into account the realities and effects of the funding. In other words, no proper preliminary and comprehensive analysis of the effects of these actions is done, causing serious retardation of sectors with strong added value and potential for rapid development compared to other sectors with not so high added value. The result is an uneven development of the region. It can be overcome through guidance from the central, regional and municipal administration concerning the potential value added of the projects to be submitted to the potential applicants. Such option could be updating the areas of soil productivity and climate dependency of specific crops.

The public should be informed about these analyzes to ensure that before an investment decision is made the applicant will know if the climate is suitable for the specific crop. This approach will reduce administrative barriers and costs to the initiatives of candidates. It will also improve the potential for creating new jobs in rural areas.

\section{Conclusions and recommendations}

The investment of public funds in activities that would bring less resource than invested is a waste of money. Loss of resources can jeopardize the long-term development of any region. When funds are not recoverable, there is a waste of opportunity for an increase in welfare.

On the basis of the above, it could be considered that implementing a method to improve the effectiveness and simplification of the process of decision-making, taking into account practical implementation would lead to better management of public funds. The City of Vienna already implements such method. ${ }^{5}$

First of all, is a necessary to work with mix of evaluating and implementing tools including: Impact assessment, Ex-ante report, effects of the implementation of the RDP measures, the Balanced Scorecard, Customer Relationship Management and Enterprise Resource Planning could increase the effectiveness of the implementation of this policy.

Second, on the base of need assessment it will be possible to evaluate the feasible effects of the implementation of the RDP measures - costs and benefits of the implementation of each measure.

The simplification and effects of the implementation of the RDP measures are a new element of analysis. This review has to include analyse of the impact as well as of the costs and benefits of the implementation of each measure.

${ }^{5}$ Municipality source (2006) Review 2006. International activities of the City of Vienna. Retrieved 06.11.2014 from

http://www.wien.gv.at/english/politics/international/mdeui/publications/pdf/report06.pdf 
Third, it is necessary to introduce the Enterprise Resource Planning and Customer Relationship Management system at Paying Agency level in order to ensure that the basis for analysis will be available which will lead to optimal resource management. This basis will give clear information about the state of the Program implementation and will allow for proper planning of future steps.

The Enterprise Resource Planning therefore and Customer Relationship Management can be based on Balanced Scorecard system6, taking into consideration the capability of that system for completeness of the scope.

The effectiveness of RDP implementation processes leads to simplifying the implementation of the program. This will significantly reduce bureaucracy in the management of the RDP and hence simplifies the implementation of the CAP. It is important to note that avoiding frequent changes of rules for the implementation of the RDP is an essential condition for smooth operation of the programme.

In conclusion, the introduction of the Enterprise Resource Planning, Customer Relationship Management, as well as the proposed analyse the Effects of the implementation of the Rural Development Program measures will lead to effectiveness of the management decision, contributing to high-value added investments for the region and country. This will have positive reflect in effectiveness and simplification of the state administration decisionmaking processes in the field of rural development policy. This will positive reflect in effectiveness and simplification of the state administration decision-making processes in the field of rural development policy.

\section{References}

1. Kaplan, R.S., and Norton, D.P (2005). The Balanced Scorecard: Translating Strategy into Action, Original work Copyright 1996 by the president and fellows of Harvard College Harvard Business School Press

2. Kaplan, R.S., and Norton D.P (2006). Strategy Maps Converting Intangible Assets into Tangible Outcomes, Copyright 2004 Harvard Business School Publishing Corporation

\section{Electronic Sources:}

1. Bulgarian Ministry of Agriculture (2014) Program for Rural Development 20072013, Retrieved October 03, 2014 from

2. http://www.prsr.bg/documents/ПРОГРАМА-ЗА-РАЗВИТИЕ-НА-СЕЛСКИТЕРАЙОНИ-(2007--2013)/4/0/index.html or http://prsr.government.bg/index.php/en/Bulgarian Ministry of Agriculture (2014) Mid-term evaluation of the Rural Development Program 20072013, Retrieved October 13, 2014 from http://prsr.government.bg/index.php/en/sections/12/55

\footnotetext{
${ }^{6}$ Kaplan, R.S. and Norton, D.P (2005). The Balanced Scorecard: Translating Strategy into Action
} 
3. European Commission Staff Working Paper (20.10.2011) Impact Assessment, Common Agricultural Policy Towards 2020, SEC(2011) 1153 final/2 Retrieved 15.10.2014 from

4. http://ec.europa.eu/agriculture/policy-perspectives/impact-assessment/cap-towards2020/report/full-text_en.pdf

5. European Commission (2013), Smart-regulation, Impact Key document, Impact Assessment Board Report for 2013, Retrieved November 07, 2014 from

6. http://ec.europa.eu/smart-regulation/impact/key_docs/docs/iab_report_2013_en.pdf

7. Bulgarian Ministry of Agriculture (2012) Ex-ante Final Report for the implementation of the Rural Development Programme 2007-2013 Ministry of Agriculture and Food

8. Bulgarian Ministry of Agriculture (2012) report on the implementation of the Rural Development Programme 2007-2013 in the Republic of Bulgaria (in compliance with Art. 82(2) of Regulation (EC) No 1698/2005) Ministry of Agriculture and Food

9. Bulgarian Ministry of Agriculture (2013) report on the implementation of the Rural Development Programme 2007-2013 in the Republic of Bulgaria (in compliance with Art. 82(2) of Regulation (EC) No 1698/2005)

10. Renda, A., Schrefler, L., Luchetta, G., Zavatta, R., (2013) CEPS Study for the European Commission, Secretariat General, Assessing the costs and benefits of regulation final report Brussels, Retrieved November 07, 2014 from

11. http://ec.europa.eu/smartregulation/impact/commission_guidelines/docs/131210_cba_study_sg_final.pdf

12. Bulgarian Ministry of Agriculture and Food September (2014) Final ex ante report BG Rural Development Program 2014-2020

13. Municipality source (2006) Review 2006. International activities of the City of Vienna, Retrieved November 07, 2014 from

14. http://www.wien.gv.at/english/politics/international/mdeui/publications/pdf/report0 6.pdf

\section{About the Authors:}

Svilen KOLEV, PhD Student; University of National and World Economy (UNWE), Sofia, Bulgaria; Department Economics of Natural Resources. Bulgaria.

Roumiana ATANASSOVA, PhD, Lecturer, New Bulgarian University, Sofia, 